\title{
HIPERTEXTO NO JORNALISMO: UMA PROPOSTA DE CARACTERIZAÇÃO DO HIPERTEXTO JORNALÍSTICO \\ HYPERTEXT IN JOURNALISM: A PROPOSAL TO CHARACTERIZE JOURNALISTIC HYPERTEXT
}

Alciane Nolibos Baccin ${ }^{*}$

\section{RESUMO:}

Este artigo tem como objetivo apresentar uma proposta de aplicação da Teoria do Hipertexto de Landow, com base na literatura, ao campo do jornalismo. Essa proposta surgiu da identificação de adequação dessa Teoria aos estudos de jornalismo digital, a partir da análise feita de produtos jornalísticos digitais. Com forte inspiração na Teoria do Hipertexto, nossa proposta define como características do hipertexto jornalístico a tipologia dos links, a multivocalidade e a estrutura de navegação. A intenção, com este trabalho, é contribuir para os estudos das especificidades das narrativas jornalísticas hipermídia.

\section{PALAVRAS-CHAVE:}

Hipertexto, narrativa jornalística, jornalismo digital.

\section{ABSTRACT:}

This article presents a proposal to apply Landow's Hypertext Theory, a literary concept, to the field of Journalism. This proposal arose from the identification of adequacy of this theory to the studies of digital journalism based on analysis concerning digital journalistic products. With a strong inspiration in Hypertext Theory, our proposal defines the hyperlink typology, multivocality and navigation structure as characteristics of journalistic hypertext. This paper contributes to studies on the characteristics of hypermedia journalistic narratives.

\section{KEYWORDS:}

Hypertext, narrative journalism, digital journalism.

1* Professora do Programa de Pós-Graduação em Comunicação e Indústria Criativa (PPGCIC) e do curso de Jornalismo da Universidade Federal do Pampa (UNIPAMPA) e doutora em Comunicação e Informação pela Universidade Federal do Rio Grande do Sul (UFRGS) e em Ciências da Comunicação pela Universidade da Beira Interior (UBI-Covilhã-Portugal). alcianebaccin@unipampa.edu.br 


\section{INTRODUÇÃO}

A discussão proposta neste artigo surge do desafio de estudar narrativas jornalísticas hipermídia a partir da Teoria do Hipertexto. Desde os primeiros estudos sobre hipertexto na área da literatura nos anos 1960, o espaço de escrita digital passa por transformações, por isso nosso interesse de compreender como as narrativas jornalísticas hipermidiáticas contemporâneas se configuram neste espaço. Com o avanço dos estudos sobre hipertexto, a partir dos teóricos George Landow (1987, 1995, 1997, 2009), Michael Joyce (1991, 1995), Michael Joyce et al. (1989) e Jay Bolter (2001), a Teoria do Hipertexto tomou forma e começou a balizar estudos sobre as narrativas em ambiente digital em várias áreas do conhecimento (linguística e literatura; filosofia e sociologia; tecnologia; educação; e jornalismo).

No campo do jornalismo, a Teoria do Hipertexto tem reflexo nos estudos sobre jornalismo digital nos anos 1990 e 2000, nas produções científicas no Brasil (LONGHI, 1998, 2003, 2004; MIELNICZUK, 2003, 2005; MIELNICZUK; PALACIOS, 2002; PALACIOS, 1999) e também no exterior (BERNSTEIN, 1998, 2000; CANAVILHAS, 2007, 2008a, 2008b; DÍAZNOCI, 2001; LARRONDO URETA, 2008; ORIHUELA, 2002; PAJARES TOSCA, 2003; PAVLIK, 2001, 2005; PÉREZ MARCO, 2003; PRYOR, 2002; SALAVERRÍA, 2005).

Desde a segunda metade da década de 2000, no entanto, percebemos escassez de estudos de jornalismo que acionem a Teoria do Hipertexto. Esse período coincide com o desenvolvimento de produtos jornalísticos para formatos digitais, entre eles as grandes reportagens em hipermídia ${ }^{1}$, foco de estudos nossos anteriores que motivaram a busca pela Teoria do Hipertexto. Ao identificarmos esse período de lacuna de estudos sobre hipertexto com foco nas produções jornalísticas digitais, assumimos o desafio de retomar a Teoria para compreendermos essas narrativas.

Ao longo dos estudos sobre a configuração de narrativas digitais nas reportagens hipermídia, sentimos a necessidade de atualização e de adequação para o campo do jornalismo da Teoria do Hipertexto. Essa necessidade partiu, primeiramente, do conhecimento de que essa Teoria, sendo elaborada com base nas narrativas ficcionais, pede uma adequação para o campo do jornalismo. E em segundo lugar, porque entendemos que tanto o espaço de escrita digital quanto o jornalismo passaram e passam por transformações contínuas que requerem um olhar atual (a última atualização da Teoria do Hipertexto feita por Landow data de 2005). 
Ao retomarmos os estudos de hipertexto, desde Nelson $(1965,1987)$, Nelson, Smith e Mallicoat (2007) e Landow (1987, 1995, 1997, 2009) chegando a Bernstein (2016), e passando pelos estudos da Teoria do Hipertexto aplicada ao jornalismo, percebemos que as características do hipertexto identificadas por Landow (1995, 1997, 2009) apresentam limitações para a análise do hipertexto no jornalismo. Por esse motivo, interessa-nos aqui apresentar uma proposta de caracterização do hipertexto jornalístico, partindo dos primórdios dos estudos sobre hipertexto até o desenvolvimento da Teoria do Hipertexto e sua transposição ao campo jornalístico.

\section{TEORIA DO HIPERTEXTO}

A história mostra que já existiam formas de escrita e de leitura não lineares antes mesmo da era eletrônica ou da digital, alguns dos exemplos clássicos são as notas de rodapé e os sumários. É a partir da necessidade de armazenar o conhecimento e associá-lo entre si que surgem as primeiras iniciativas que, mais tarde, vão originar a hipertextualidade. Em 1945, o físico e matemático norte-americano Vannevar Bush desenvolve uma máquina para uso individual, a qual batiza de Memex. No dispositivo cada indivíduo poderia armazenar todos os seus livros, registros e comunicações, para consultar quando quisesse. Além de armazenar uma biblioteca multimídia de documentos, via microfilmes, o Memex também possibilitava associações não lineares entre documentos e permitia que o usuário adicionasse comentários aos arquivos. Bush (1945) acreditava que o dispositivo imitaria as associações e conexões mentais, alargando a memória humana. Assim nasce a ideia de um dos elementos mais importantes do hipertexto: o link.

Somente em 1960, o termo hipertexto é usado pela primeira vez. Ted Nelson desenvolve o Projeto Xanadu² com o intuito de criar uma biblioteca universal, na qual os usuários interagiriam simultaneamente. Para Nelson, é imprescindível que o leitor tenha total liberdade, selecionando qual caminho hipertextual seguir de acordo com seus interesses e total acesso ao mundo do conhecimento. Assim como Bush, Nelson pensa a escrita hipertextual por associações, como a mente humana. Nelson cria o termo "hipertexto" para descrever o funcionamento de sua invenção - a plataforma de computação Xanadu. Nelson mantém pesquisas atuais e muitas de suas ideias foram e são implantadas nos sistemas informatizados hipertextuais.

Na década de 1980, foram vários os avanços tecnológicos no campo da informática e da internet, principalmente a expansão dos usos dos computadores, a viabilidade 
comercial dos sistemas de hipertexto e a ampliação da internet - este permitiu o abrigo de um conjunto de documentos hipertextuais com informações digitalizadas de textos, sons e imagens, conectados entre si e espalhados por computadores do mundo inteiro, o que protagonizou a invenção de Tim Berners-Lee e Robert Cailliau - a World Wide Web, em $1990^{3}$.

Nesse período, também se ampliam os estudos e as discussões sobre os conceitos que definem o hipertexto. Em 1987, a Association of Computing Machinery (ACM) realiza o primeiro evento acadêmico sobre hipertexto - ACM Conference on Hypertext - o qual é promovido anualmente até hoje ${ }^{4}$, e reúne pesquisadores e estudantes de várias áreas, como computação, artes, linguística e comunicação.

O hipertexto é potencializado com a escrita digital. A escrita, de um modo geral, sempre na história da humanidade, esteve atrelada a um espaço e a uma tecnologia (argila, couro, papel). A escrita digital é “um campo material e visual, cujas propriedades são definidas por uma determinada tecnologia de escrita"5 (BOLTER, 2001, p. 12, tradução nossa). No espaço digital, o campo físico e visual é topográfico, porque não possui limites pré-estabelecidos para se desenvolver, diferente de todos os espaços anteriores, que eram limitados. Essa é uma característica que inova o lugar de escrita, desestabilizando os limites textuais e potencializando o hipertexto. Com a textualidade digital, a escrita, que até então era física, converte-se em códigos. Esses códigos, por sua vez, podem ser alterados, são flexíveis. A regra da qual derivam os processadores de texto é "muda o código, muda o texto"6 (LANDOW, 2009, p. 126). Mas é importante ressaltarmos que o espaço de escrita não se caracteriza só pela tecnologia, a interação do escritor e do leitor com esse espaço também o define, pois segundo Bolter (2001, p. 20, tradução nossa) "é a soma de interações técnicas e sociais que constituem um sistema de escrita"7.

Além da alteração que ocorre no espaço físico da escrita digital, inclusive amplificado pela memória dos dispositivos, o espaço visual também é modificado. Na escrita digital, o espaço visual é multidimensional, porque há algo oculto que está em outras camadas de informação. Essa multidimensionalidade é possibilitada pelo hipertexto. Bernstein et al. (1991) destacam ainda que no espaço de escrita, as relações que se estabelecem vão além da interação com o conteúdo, porque os usuários manipulam também a estrutura diretamente, organizando, abrindo e fechando cada fragmento, levando os escritores a ver o trabalho como um conjunto de componentes ou tópicos significativos. 
A Teoria do Hipertexto parte do viés da teoria crítica literária para pensar a escrita hipertextual e a narrativa. A Teoria do Hipertexto defende na literatura a necessidade de abandonar o modelo de escrita que se materializa no impresso, baseado em noções de centralidade, hierarquia e linearidade, para dar espaço para uma escrita mais aberta, que admita a multilinearidade, construída por blocos de informação, hiperlinks e redes. A concepção do texto aberto, requerida pelos pós-estruturalistas, potencializa-se no hipertexto, porque permite ao leitor a seleção, a combinação e o aprofundamento dos e nos hiperlinks. Outro ponto importante do pensamento crítico que o hipertexto fomenta é a busca, tanto na escrita quanto na leitura, pelas diversas causas que incidem sobre o fenômeno inscrito ou sobre a história contada - uma busca que leva à contextualização, ao complemento e ao aprofundamento da informação. A partir da concepção dessa escrita mais aberta, Landow (1987, 1995, 1997, 2009) contribui para a construção de uma teoria que sustenta o discurso acadêmico em torno do hipertexto. Na conceituação dessa Teoria do Hipertexto, o autor apresenta características que seriam definidoras do hipertexto.

\section{AS CARACTERÍSTICAS DO HIPERTEXTO NA LITERATURA}

O desenvolvimento do hipertexto como área de conhecimento científico se inicia na década de 1980, quando as pesquisas se ramificaram em vários campos do conhecimento: da linguística, da literatura, da filosofia, da sociologia, da tecnologia, da educação e do jornalismo. A Teoria do Hipertexto, proposta por Landow (1987, 1995, 1997, 2009), identifica características que o hipertexto apresenta nas narrativas construídas para e no espaço de escrita digital. De acordo com a Teoria, essas características são: intertextualidade, multivocalidade, descentralização, rizoma e intratextualidade:

- Intertextualidade: essa característica tem como base a proposta de abertura textual de Derrida (1971), para o qual o texto é composto de unidades discretas de leitura. O que também se relaciona com o conceito de lexias de Barthes (1992), que se refere às unidades de leitura de um texto. É essa característica que permite tornar mais explícito o que se relaciona com o texto, seja por iniciativa do leitor ou uma ação já prevista pelo próprio autor. Mielniczuk (2003, p. 99) destaca que o hipertexto é essencialmente um sistema intertextual, porque "as referências feitas a outros textos são potencializadas no hipertexto através do recurso do link, que realiza as conexões entres os blocos de textos”. O hipertexto torna mais 
explícito o material que rodeia a obra, abrindo o texto para uma gama de relações com outros textos e liberando o usuário à percepção de múltiplas interconexões.

- Multivocalidade: é uma característica que se baseia na teoria literária de Bakhtin (1981), principalmente nos conceitos de dialogismo, polifonia e multiplicidade de vozes, que se formam a partir do conjunto de várias consciências. Landow (2009) sustenta a possibilidade de coexistência de diversas vozes na narrativa, porque no hipertexto não há uma "única voz tirânica”, a voz sempre se origina da experiência. Porém pouco explica a aproximação entre a ideia de multivocalidade no hipertexto e os conceitos da teoria literária, o que, segundo Mielniczuk (2003, p. 100) acarreta certa confusão, podendo ser entendido de duas formas: “a primeira, no sentido de múltiplas vozes, relativa à construção de uma narrativa literária e a segunda, num sentido mais operacional, relacionada com a cooperação de vários autores para a criação de um mesmo texto ou narrativa”. Landow (2009) retoma o conceito de polifonia de Bakhtin (1981, p. 181): “o nosso discurso da vida prática está cheio de palavras de outros. Com algumas fundimos inteiramente a nossa voz, esquecendo-nos de quem são; com outras, reforçamos nossas próprias palavras [...]; por último, revestimos terceiras das nossas próprias intenções”. A conceituação de polifonia de Bakhtin pode abarcar as duas formas de interpretação, tanto a que a narrativa do autor já é uma multiplicidade de vozes quanto a de escrita cooperativa.

- Descentralização: com influência do pensamento de Derrida sobre descentramento, o hipertexto está composto por vários fragmentos de textos conectados, formando um sistema em que o leitor escolhe o centro de experiência, no qual "o hipertexto se experimenta como um sistema que se pode descentrar e recentrar até o infinito, em parte porque transforma qualquer documento que tenha mais de um link em um centro passageiro"8 (LANDOW, 2009, p. 89, tradução nossa). Isso quer dizer que o texto principal é determinado pela lexia, nó ou fragmento que o leitor está lendo no momento, na medida em que acessa outra lexia o centro se desloca também. A descentralização se refere também à ausência de uma hierarquização mais rígida dos textos, como ocorre no impresso.

- Rizoma: essa característica está intimamente relacionada com o conceito de Rizoma desenvolvido por Deleuze e Guattari (1995). Esse conceito abrange seis princípios: $1^{\circ}$ e $2^{\circ}$ Conexão e Heterogeneidade, reúnem a ideia de que qualquer 
ponto de um rizoma pode ser conectado a qualquer outro; $3^{\circ}$ Multiplicidade, trata o múltiplo como substantivo e se define pelo que está fora abarcando acontecimentos vividos, determinações históricas, conceitos pensados, indivíduos, grupos e formações sociais; $4^{\circ}$ Ruptura assignificante, diz respeito às rupturas contínuas que o rizoma pode sofrer e nas múltiplas segmentaridades que pode adotar, há ruptura no rizoma cada vez que linhas segmentares explodem em uma linha de fuga e compõem o rizoma; $5^{\circ}$ e $6^{\circ}$ Cartografia e Decalcomania, o mapa é uma experimentação ancorada no real, não uma reprodução como o é o decalque. 0 mapa “deve ser produzido, construído, sempre desmontável, conectável, reversível, modificável, com múltiplas entradas e saídas, com suas linhas de fuga. São os decalques que precisam referir aos mapas e não o inverso" (DELEUZE; GUATTARI, 1995, p. 15). O rizoma contrapõe-se à ideia de hierarquia porque um rizoma pode conectar um ponto a qualquer outro, oferecendo muitos começos e muitos fins.

- Intratextualidade: embora Landow (1995, 1997, 2009) não deixe claro nos seus textos que considera essa uma característica do hipertexto, isso fica subentendido quando aborda a questão dos enlaces eletrônicos que podem ser utilizados "para elaborar um mapa das alusões e referências do texto, tanto internas como externas - sua inter e intratextualidade"9 (LANDOW, 2009, p. 106). A intratextualidade diz respeito às ligações internas que podem existir entre lexias dentro de uma mesma obra.

Essas características atribuídas por Landow ao hipertexto dizem respeito às narrativas ficcionais, as quais têm especificidades próprias distintas das narrativas jornalísticas. Essa ressalva é feita inclusive pelo próprio autor em uma breve referência que faz ao texto informativo no seu último livro. De acordo com Landow (2009, p. 279), o hipertexto informativo precisa utilizar-se de retóricas de orientação, navegação e ponto de partida para que o leitor possa orientar-se na informação. Com essa afirmação do autor, percebemos que duas das características apontadas pelo teórico, o rizoma e a descentralização, que fazem referência à ausência de hierarquização narrativa, na qual o leitor poderia escolher a trajetória de leitura e construir a própria história, não caracterizam o hipertexto informativo; bem como há escassez de intertextualidade nas produções jornalísticas. Também reconhecemos que os estudos sobre hipertexto precisam acompanhar as transformações pelas quais passam as narrativas jornalísticas. Por isso, 
entendemos a importância da atualização da Teoria do Hipertexto e de sua adequação ao campo do jornalismo.

\section{PROPOSTA DE CARACTERIZAÇÃO DO HIPERTEXTO JORNALÍSTICO}

A Teoria do Hipertexto serviu de base para as discussões e para a construção de conceitos e argumentos que atualizam e adequam a Teoria ao campo dos estudos jornalísticos. Procuramos, primeiramente, reconhecer esse espaço de escrita digital, o qual abarca as narrativas jornalísticas. O espaço físico da escrita digital é constituído por camadas de softwares que transformam os circuitos eletrônicos em espaço de informação simbólica, no qual o espaço visual são as interfaces com as quais interagimos. As aproximações costuradas ao longo dos nossos estudos, entre a Teoria do Hipertexto, os estudos sobre hipertextualidade e o campo do jornalismo, levam-nos a identificar que as Teorias do Hipertexto, como foram pensadas a partir da literatura, não estão plenamente adequadas às narrativas jornalísticas. Ao olharmos para o nosso objeto, percebemos que algumas características do hipertexto, como rizoma e intertextualidade, não são comuns às narrativas jornalísticas no espaço de escrita digital.

Os textos jornalísticos não são rizomáticos, mesmo na web, eles apresentam hierarquia e ordem na narrativa. Os jornais evitam conduzir o leitor para fora das matérias jornalísticas, limitando assim a intertextualidade. Temos exemplos de formatos inovadores no jornalismo digital, como o longform e o podcast, que têm garantido o aproveitamento de potencialidades do meio e possibilitado que as narrativas na web e nos dispositivos móveis se reconfigurem como produto com características próprias desse ambiente (BACCIN, 2017a), mas que limitam as noções de rizoma e intertextualidade.

A Teoria do Hipertexto foi criada por Landow ao longo de, pelo menos, 15 anos, desde os primeiros textos em 1987, sempre tendo como foco as narrativas literárias. Os livros do autor que reúnem a Teoria do Hipertexto são das décadas de 1990 e 2000. A última atualização de Landow sobre a Teoria do Hipertexto foi a obra Hipertexto 3.0, publicada em $2005^{10}$. O espaço de escrita digital é dinâmico, de 2005 a 2017 muitas transformações ocorreram tanto na web quanto no jornalismo. Os autores do campo do jornalismo digital (CANAVILHAS, 2007, 2008a, 2008b; DÍAZ-NOCI, 2001; DIAZ-NOCI; SALAVERRÍA, 2003; LARRONDO URETA, 2008; LONGHI, 1998, 2003, 2004; MIELNICZUK, 2003, 2005; PALACIOS, 1999; PAVLIK, 2001, 2005; PRYOR, 2002) que fizeram aproximações com a Teoria do Hipertexto as também fizeram em outro momento. 
Refletindo, exclusivamente, sobre as narrativas jornalísticas hipermídia, com forte inspiração na Teoria do Hipertexto, identificamos como características próprias dessas histórias contadas no espaço de escrita digital: a tipologia dos links, a multivocalidade e a estrutura de navegação. Explicamos melhor cada uma delas e a influência das características apresentadas por Landow.

\section{TIPOLOGIA DOS LINKS}

O link tem um papel importante nas escritas hipertextuais, porque é por meio dele que várias lexias se conectam entre si, proporcionando o aprofundamento das informações. O link é o elemento que proporciona a intertextualidade (característica do hipertexto), porque é por meio dele que podemos interligar quaisquer informações entre si. Embora a intertextualidade já fosse possível nos textos impressos, por meio de referências a autores, a citações e a obras, no hipertexto essa característica é potencializada, em virtude do link.

No jornalismo, entendemos que o link, além de possibilitar a conexão entre textos que possam se completar, pode desempenhar outro papel importante: aferir credibilidade aos dados e às informações que o jornalista apresenta na reportagem, como, por exemplo, por meio de links às fontes de informação (base de dados, documentos originais, entrevistas e depoimentos brutos). Tanto o jornalista pode disponibilizar aos leitores o link para a fonte, como o leitor pode, por meio das hiperligações em sites de busca, acessar as fontes sem precisar de muito esforço e de deslocamento.

Os links representam uma possibilidade de ganho no jornalismo, porém De Maeyer (2012, 2013) ressalta que esse ganho ainda não é bem explorado porque “o nosso mundo social não é ainda inteiramente feito de pedaços de dados e metadados, ordenadamente mapeados e interconectados"11 (MAEYER, 2014, p. 538, tradução nossa), o que possibilitaria que as informações estivessem totalmente acessíveis, a poucos cliques de cada um de nós. Para Coddington (2014, p. 141, tradução nossa) há esperança de que “os links possam ajudar a reforçar a facticidade de uma reportagem conectando leitores diretamente às fontes e mostrando aos leitores como jornalistas sabem o que sabem"12. A possibilidade de realizar essas conexões transmite grande esperança de que as alegações do jornalismo sobre "veracidade" dos fatos relatados possam ganhar força. 
O link também é o elemento que possibilita a intratextualidade (outra característica do hipertexto apresentada por Landow (1995, 1997, 2009), que diz respeito às ligações internas que podem existir entre lexias dentro de uma mesma obra. São essas ligações que vão determinar, principalmente, a forma das narrativas (RYFE; MENSING; KELLEY, 2016). No jornalismo, essas são as ligações mais comuns. O objetivo principal dos links entre lexias de uma mesma obra é aprofundar a história, levar o leitor mais fundo ao contexto do acontecimento. É o link que possibilita a construção de camadas de informação no espaço de escrita digital, quanto mais informações o leitor desejar, mais fundo entra na narrativa, projetando-se dentro desse espaço virtual (DOHERTY, 2014). Nas reportagens hipermídia, os links também sugerem a multimidialidade, que contribui para o enriquecimento da narrativa, proporcionando que os jornalistas selecionem as formas expressivas que melhor exprimem a complexidade do que é narrado.

A partir da importância que o link tem nas histórias que são contadas no jornalismo e nos estudos aos quais nos referimos, acreditamos que o nosso foco de análise tenha que ser direcionado aos vários tipos de links que existem na reportagem e não apenas ao seu universo de abrangência, como define Mielniczuk (2003) os links internos ou externos. Isso porque, em uma pré-análise que fizemos no corpus da pesquisa, detectamos que as reportagens hipermídia praticamente não apresentam links externos. Isso nos alertou para a carência de intertextualidade nas histórias jornalísticas, de modo geral, o que ocorre devido à preocupação de editores e donos de meios de comunicação de perderem os leitores na medida em que estes acessem outros sites que não sejam o da própria organização jornalística ou do grupo de comunicação que os mantém (BARNHURST, 2010; STEENSEN, 2011). Esse entrave comercial tem inibido o uso dessa característica do hipertexto no jornalismo.

Logo, definimos como uma característica que tem como propósito reunir os tipos de links que dão conta de caracterizar as ligações estabelecidas nas reportagens hipermí$\mathrm{dia}^{13}$. Para isso nos baseamos na proposta de Mielniczuk (2003) de tipologia dos links, focando para a organização editorial, a qual se divide em links organizativos e narrativos - estes a autora subdivide em:

Acontecimento: diz respeito aos principais acontecimentos do fato noticiado.

Detalhamento: apresenta detalhes sobre o acontecimento; podem ser dados depoimentos ou explicações de especialistas. 
Oposição: quando for o caso, apresentar argumentos de entrevistados ou dados que contestem informações de fontes oficiais ou fontes primárias ouvidas.

Exemplificação ou particularização: ilustra ou explica o acontecimento com exemplos ou casos particulares, apresentando personagens ou casos semelhantes.

Complementação ou ilustração: oferece dados complementares que possam auxiliar na apresentação e compreensão do acontecimento.

Memória: oferece links que remetem ao arquivo de material já disponibilizado sobre o assunto ou assuntos correlatos (MIELNICZUK, 2003, p. 137, grifos no original).

Tendo em vista que essa tipologia foi construída há mais de 15 anos e ao longo desse tempo o jornalismo no espaço de escrita digital também aprimorou a maneira de contar histórias, acreditamos ser necessária uma adaptação. Por isso, construímos uma tipologia de links para as narrativas jornalísticas atuais. Os links nessas narrativas podem ser divididos em quatro grupos: os relativos à estrutura da navegação; os relativos à participação do público, os relativos à organização da disposição da história e os relativos, especificamente, à narração da história. Explicamos cada um dos grupos:

- Estrutura da navegação: links que se referem aos aspectos técnicos de elaboração do hipertexto, definindo a estratégia de navegação. Subdivide-se em:

- Conjuntivo: links que acessam outra lexia na mesma tela, deixando as demais lexias visíveis. 0 link conjuntivo permite que vejamos a lexia acessada como parte integrante da reportagem.

- Disjuntivo por sobreposição: links que abrem outra lexia que se sobrepõe a anterior. Esse link disjuntivo não permite que vejamos as demais lexias na mesma tela, há a necessidade de uma impor-se sobre a outra.

- Disjuntivo por opção: links que levam para outra lexia abrindo outra janela no navegador. O link disjuntivo por opção nos oportuniza a manutenção da lexia anterior em uma aba e a que acessamos por meio do link em outra.

- Participação do público: links que permitem o acesso aos espaços de comentários e aos sites de redes sociais.

- Organizativo: links que organizam a história contada por temática. São representados pelos índices que apresentam as divisões de capítulos. 
- Narrativo: links que conectam as várias lexias responsáveis por contar a história. Subdividem-se em:

- Complementação: quando os links oferecem dados ou informações adicionais que ajudam na compreensão da informação;

- Ilustração: quando os links sugerem que alguma informação vai ser mostrada, auxiliando no entendimento da história;

- Particularização: quando os links dão acesso à apresentação de casos particulares, de histórias de vida, para explicar o acontecimento, geralmente trazem personagens da história.

- Contraponto: quando os links remetem a informações que contestam dados oficiais ou depoimentos de personagens.

\section{MULTIVOCALIDADE}

A multivocalidade é entendida como uma narrativa escrita que nunca contém uma única voz, porque o próprio autor da obra sempre carrega consigo outras vozes que são expressas na obra, e também o leitor, ao ler a obra, está a interpretar conforme sua experiência de vida; e uma multivocalidade no sentido operacional, quando a obra é feita por vários autores.

No jornalismo no ambiente digital, a multivocalidade pode ser compreendida tanto como uma narrativa construída com a cooperação dos leitores - seja no envio de imagens, no relato de quem presenciou o acontecimento ou nos comentários das notícias, que contribuem com a construção e a ampliação da narrativa - seja como uma informação jornalística que é construída pelas inúmeras vozes que compõem o repórter, o editor, as fontes e até as que estão representadas na linha editorial do meio. É verdade que todas essas múltiplas vozes já eram possíveis de compor as narrativas jornalísticas antes do espaço de escrita digital, mas também é verdade que o hipertexto potencializa a participação dos leitores na construção das narrativas, sugerindo pautas, opinando sobre a edição e relatando experiências que contribuem com a história narrada, bem como a inserção de vozes em várias modalidades comunicativas diferentes (texto, vídeo, áudio) em uma mesma reportagem. 
Quando a participação dos leitores é aproveitada e estimulada no jornalismo, há expansão do espaço retórico (KOBÍKOVA, 2014). Percebemos isso não só nos sites de notícias que acolhem a participação dos leitores, como também nas mídias sociais digitais, como Facebook, Twitter, Instagram e outras que ainda virão, nas quais o espaço de fala é aberto e propício à participação. Para isso, os repórteres e editores precisam investir em diferentes formas de contar histórias para diferentes públicos e diferentes finalidades, principalmente no que diz respeito à exploração do papel da animação, da apresentação multilinear e da interatividade dilatada pelos infográficos, ampliando a compreensão das histórias.

O hipertexto jornalístico aproxima a comunicação entre leitores e jornalistas podendo resultar em discurso hipernarrativo polifônico (LARRONDO URETA, 2009), em que a narrativa é enriquecida com maior ou menor participação do leitor e com a possibilidade de ampliação de vozes, tanto pelo espaço menos limitado quanto pelas relações que possam ser estabelecidas com outros textos, por meio de links.

\section{ESTRUTURA DE NAVEGAÇÃO}

A ideia de Landow (2009) de que o hipertexto é composto por fragmentos de textos conectados, formando um sistema no qual o leitor escolhe o centro de experiência e sem um eixo primário de organização parte da influência do pensamento de Derrida sobre descentramento, em que “o hipertexto se experimenta como um sistema que se pode descentrar e recentrar até o infinito, em parte porque transforma qualquer documento que tenha mais de um link em um centro passageiro"14 (LANDOW, 2009, p. 89). A descentralização se refere à ausência de uma hierarquização das lexias. As pesquisas sobre hipertexto repousam sobre a convicção de que a informação é ricamente estruturada e que quando essa estrutura é expressa amplia-se a capacidade de compreensão e de utilização dessas informações. Essa descentralização pode ocorrer nas narrativas jornalísticas quando estruturadas na ideia do hipertexto espacial. Nem sempre a estrutura de informação é explícita, mas a ideia é que o hipertexto espacial proporcione meios rápidos e informais para expressar as relações possíveis. 0 hipertexto espacial funciona como um organizador conceitual, proporcionando aos usuários a capacidade visual e espacial para organizar e interpretar a informação.

Os sistemas como VIKI e Storyspace se baseiam em nossa "inteligência espacial" usando interfaces gráficas para organizar ideias complexas (SHIPMAN et al., 2002). Para 
interpretar um hipertexto espacial, temos que decodificar como a organização de lexias no espaço reflete as relações entre si ou o que essas lexias representam. Os benefícios das representações espaciais e das interfaces contemplam tanto escritores quanto leitores, porque o hipertexto espacial proporciona aos leitores uma oportunidade para que a leitura ocorra em contexto, com consciência dos nós relacionados, e aos escritores permite explorar diversas estruturas para melhor contar a história. Já existem iniciativas no jornalismo de estruturas explícitas espaciais e narrativas que se constroem a partir de fotografias, gravuras ou ícones, nas quais os links são dispostos no espaço da imagem. Nesses casos, a noção de descentralização das lexias é ainda mais evidente.

A noção de espacialidade também é presente nos hipertextos esculturais, os quais representam um espaço hipertextual por meio do qual o leitor se move para testemunhar e, talvez, participar da ação. Os autores Blount, Scott e Millard (2016) e Hargood et al. (2016) estudam e atualizam possibilidades da construção de narrativas baseadas em hipertexto escultural a partir da localização do leitor. De acordo com os autores, essa é uma forma emergente de narrativas digitais que usam tecnologias de localização para acionar conteúdo em dispositivos inteligentes de acordo com a localização do usuário.

Landow (1995, 1997, 2009) defende que a descentralização é característica dos hipertextos literários e poéticos. No jornalismo, as informações são organizadas hipertextualmente a partir de um eixo central que conduz as histórias. A descentralização não se efetiva nas narrativas jornalísticas no espaço de escrita digital. Isso ocorre com outra característica do hipertexto, identificada por Landow (1995, 1997, 2009), o rizoma. O próprio Landow admite que “o rizoma é essencialmente um contraparadigma, não algo realizável em algum tempo ou cultura, mas que pode servir como ideal para o hipertexto”15 (LANDOW, 2009, p. 95, tradução nossa). Por isso, algumas particularidades do rizoma convergem com o hipertexto jornalístico. O mais visível é a questão da multilinearidade, que permite ao leitor escolher o caminho que seguirá na narrativa jornalística, conforme seu interesse por mais informação, porém dentro de limites das especificidades jornalísticas, como coerência e coesão.

Na reportagem hipermídia, por exemplo, o leitor pode eleger seguir a sequência estabelecida pelos repórteres e editores ou escolher alternar a leitura entre os capítulos da reportagem. Como bem salienta Larrondo Ureta (2009, p. 72, tradução nossa), “essa escrita fragmentada não implica em si mesma uma ausência de organização ou ordem lógica, já que o autor mantém sua responsabilidade de articulação hierárquica de todo 
o conjunto"16. No hipertexto informativo o enlace coerente e relevante é necessário. De acordo com Landow (2009, p. 279, tradução nossa), a diferença do hipertexto informativo para o de ficção é que o informativo "tem de servir-se de retóricas de orientação, navegação e ponto de partida para orientar o leitor” ${ }^{17}$.

A partir dessa constatação de Landow (2009), de que o hipertexto jornalístico requer retóricas de orientação, navegação e ponto de partida, percebemos que nas narrativas jornalísticas hipermídia as características de descentralização e rizoma, identificadas pelo autor, não se efetivam na plenitude, apenas particularidades de uma e de outra estão presentes nas histórias contadas pelo jornalismo. Logo, propomos uma característica que dê conta de analisar essas retóricas de orientação, navegação e ponto de partida nas narrativas jornalísticas hipermídia, a estruturação da navegação. Essa característica retoma o grupo de links relativo à estrutura de navegação, para compreendermos qual estrutura é expressa nas narrativas jornalísticas hipermídia e de que forma.

Os links conjuntivos e disjuntivos por sobreposição e por opção definem as estratégias de navegação das narrativas, as quais também interferem no entendimento das histórias contadas pelo jornalismo. Os links conjuntivos mantêm a simultaneidade das lexias, isso quer dizer que é possível acessarmos um link dentro da reportagem sem que as demais lexias, que estamos visualizando na tela, fiquem ocultas. Já os links disjuntivos separam a lexia acessada do restante da reportagem, isso pode ocorrer por sobreposição, quando a lexia acessada pelo link se sobrepõe às lexias que estávamos visualizando, tomando o lugar do restante da reportagem, ou por opção, quando ao acessarmos o link, a lexia abre em outra janela do navegador, separando-se da janela na qual se desenvolve a reportagem.

As três características - tipologia dos links, multivocalidade e estruturação da navegação - são contribuições iniciais apresentadas por nós com o objetivo de compreender as narrativas jornalísticas hipermídia. Essas especificidades do texto jornalístico no espaço de escrita digital têm forte inspiração nas características do hipertexto literário destacadas por Landow (1995, 1997, 2009), mas procuram mais identificação com as particularidades jornalísticas e com as iniciativas de reportagens hipermídia que têm surgido nesse espaço. Esse desenvolvimento teórico propõe um deslocamento da Teoria do Hipertexto, baseada na literatura, para o jornalismo, adequando as características para esse ambiente de narrativas. 
Reconhecemos que as narrativas jornalísticas digitais estão em constantes transformações, abrigando iniciativas como o longform (BACCIN, 2017a; DOWLING; VOGAN; 2015; LONGHI; WINQUES, 2015; SHARP, 2013) e o podcast (KISCHINHEVSKY, 2018). Nosso interesse pela hipertextualidade no jornalismo permanece, por conta disso outros estudos estão em andamento para identificarmos o potencial e as inovações adotadas nesses formatos jornalísticos, a partir da hipertextualidade.

\section{CONSIDERAÇÕES FINAIS}

O movimento de deslocar a Teoria do Hipertexto dos estudos de literatura para pensar as narrativas jornalísticas hipermídia nos levou a compreender que, embora essa Teoria ainda dê conta de explicar a hipertextualidade nas construções narrativas ficcionais e, por um tempo, também tenha sido acionada no campo do jornalismo para a compreensão dos produtos jornalísticos na web, está aberta a reflexões mais aprofundadas que levem em conta também as especificidades jornalísticas e as próprias transformações do jornalismo no ambiente digital.

Ao longo dos estudos e pesquisas realizadas, fomos ampliando a compreensão da Teoria do Hipertexto, proposta por Landow e adotada por outros teóricos (BERNSTEIN, 1998, 2000, 2016; BOLTER, 2001; JOYCE, 1991, 1995; JOYCE et al., 1989; MIELNICZUK, 2003, 2005; PALACIOS, 1999, para citar alguns), e assumimos o desafio de delinear uma proposta de caracterização do hipertexto jornalístico, que nos levou as três características apresentadas neste trabalho: tipologia dos links, multivocalidade e estrutura de navegação. Este exercício de refletir sobre a Teoria do Hipertexto aplicada ao jornalismo e as particularidades do hipertexto em narrativas jornalísticas hipertextual contribui para a análise dos produtos jornalísticos na web.

A partir da Teoria do Hipertexto, podemos concluir que o hipertexto tem potencial para ser mais bem explorado nas narrativas jornalísticas em ambiente digital, pois ele abre possibilidades de inovação no jornalismo, tanto viabilizando formatos variados de produtos hipermidiáticos quanto ampliando os modos de o jornalista contar histórias nesse espaço. Acreditamos que a definição de características próprias das narrativas jornalísticas hipertextuais possa assumir um papel importante nos estudos de jornalismo digital, abrindo novas perspectivas de estudos sobre a hipertextualidade no campo jornalístico, principalmente no que se refere às potencialidades que essas características oferecem às narrativas jornalísticas. 


\section{REFERÊNCIAS}

BACCIN, Alciane. A narrativa longform em reportagens hipermídia. Estudos em Jornalismo e Mídia, Florianópolis, v. 14, n. 1, p. 89-101, 2017a.

BACCIN, Alciane. Como contar história? O hipertexto jornalístico na reportagem hipermídia. 2017. 324 f. Tese (Doutorado em Comunicação) - Universidade Federal do Rio Grande do Sul, Porto Alegre, 2017b. Disponível em: https://lume.ufrgs.br/handle/10183/158497. Acesso em: 7 ago. 2020.

BAKHTIN, Mikhail. Problemas da poética de Dostoiévski. Rio de Janeiro: Forense Universitária, 1981.

BARNHURST, Kevin. The form of reports on U.S. newspaper sites, an update. Journalism Studies, Abingdon, v. 11, n. 4, p. 555-566, 2010.

BARTHES, Roland. S/Z: uma análise da novela Sarrasine de Honoré de Balzac. Tradução Léa Novaes. Rio de Janeiro: Nova Fronteira, 1992.

BERNSTEIN, Mark. More than legible: on links that readers don't want to follow. In: ACM CONFERENCE ON HYPERTEXT AND HYPERMEDIA, 11., 2000, San Antonio. Proceedings [...]. New York: ACM, 2000. p. 216-217.

BERNSTEIN, Mark. Patterns of hypertext. In: ACM CONFERENCE ON HYPERTEXT, 9., 1998, Pittsburgh. Proceedings [...]. New York: ACM, 1998. p. 21-29.

BERNSTEIN, Mark. Thoughts about writing an exciting hypertext. Watertown, 2016. Disponível em: http://ceur-ws.org/Vol-1628/nht_paper_2.pdf. Acesso em: 7 ago. 2020.

BERNSTEIN, Mark et al. Architectures for volatile hypertext. In: ACM CONFERENCE ON HYPERTEXT, 3., 1991, San Antonio. Proceedings [...]. New York: ACM, 1991. p. 243-260.

BLOUNT, Tom; SCOTT, Jonathan; MILLARD, David. Yarncraft: location aware narratives in virtual space. In: NARRATIVE AND HYPERTEXT CONFERENCE, 2016. Disponível em: https://pdfs.semanticscholar. org/76cb/3638186bd06424b450d36f048af7d081fa67.pdf?_ga=2.142544498.1762300768.15968409971270842473.1596840997. Acesso em: 7 ago. 2020.

BOLTER, Jay David. Writing space: computers, hypertext, and the remediation of print. New York: Routledge, 2001.

BUSH, Vannevar. As we may think, The Atlantic Monthly, Boston, v. 176, n. 1, p. 101-108, 1945. CANAVILHAS, João. Cinco Ws e um H para o jornalismo na web. Revista Prisma.com, Porto, n. 7, p. 153-172, 2008a. 
CANAVILHAS, João. Hipertexto e recepção de notícias online. BOCC - Biblioteca Online de Ciências da Comunicação, [S.l.], p. 1-19, 2008b. Disponível em: http://www.bocc.ubi.pt/pag/canavilhas-joaohipertexto-e-recepcao-noticias-online.pdf

CANAVILHAS, João. Webnoticia: propuesta de modelo periodístico para la www - vol. 1. Covilhã: Livros Labcom, 2007.

CODDINGTON, Mark. Normalizing the hyperlink: how bloggers, professional journalists, and institutions shape linking values. Digital Journalism, Abingdon, v. 2, n. 2, p. 140-155, 2014.

DE MAEYER, Juliette. L'usage journalistique des liens hypertextes: étude des représentations, contenus et pratiques à partir des sites d'information de la presse belge francophone. 2013. 281 f. Tese (Doutorado em Informação e Comunicação) - Faculdade de Filosofia e Letras, Universidade Livre de Bruxelas, Bruxelas, 2013. Disponível em: https://difusion.ulb.ac.be/vufind/Record/ULBDIPOT:oai:dipot.ulb.ac.be:2013/209443/TOC. Acesso em: 7 ago. 2020.

DE MAEYER, Juliette. The journalistic hyperlink: prescriptive discourses about linking in online news. Journalism Practice, Abingdon, v. 6, n. 5-6, p. 692-701, 2012. Disponível em: https://www. tandfonline.com/doi/abs/10.1080/17512786.2012.667273. Acesso em: 7 ago. 2020.

DELEUZE, Gilles; GUATTARI, Felix. Introdução: rizoma. In: DELEUZE, Gilles.; GUATTARI, Felix. Mil platôs: capitalismo e esquizofrenia. São Paulo: Editora 34, 1995. v. 1, p. 11-38.

DERRIDA, Jacques. De la gramatología. Buenos Aires: Siglo Veintiuno Argentina Editores, 1971. DÍAZ-NOCI, Javier. La escritura digital: hipertexto y construcción del discurso informativo en el periodismo electrónico. Bilbao: Universidad del País Vasco, Servicio Editorial, 2001.

DÍAZ NOCI, Javier; SALAVERRÍA, Ramón. Manual de redacción ciberperiodística. Barcelona: Ariel, 2003.

DOHERTY, Skye. Hypertext and journalism: paths for future research. Digital Journalism, Abingdon, v. 2, n. 2, p. 124-139, 2014.

DOWLING, David; VOGAN, Travis. Can we 'Snowfall' this? Digital longform and the race for the tablet market. Digital Journalism, Abingdon, v. 3, n. 2, p. 209-224, 2015.

HARGOOD, Charlie et al. Patterns of sculptural hypertext in location based narratives. In: ACM CONFERENCE ON HYPERTEXT, 27., 2016, Halifax. Proceedings [...]. New York: ACM, 2016. p. 61-70. JOYCE, Michael. Of two minds: hypertext pedagogy and poetics. Ann Arbor: University of Michigan Press, 1995. 
JOYCE, Michael. Storyspace as a hypertext system for writers and readers of varying ability. In: ACM CONFERENCE ON HYPERTEXT, 3., 1991, San Antonio. Proceedings [...]. New York: ACM, 1991. p. 381387.

JOYCE, Michael et al. Hypertext, narrative, and consciousness. In: ACM CONFERENCE ON HYPERTEXT, 2., 1989, New York. Proceedings [...]. New York: ACM, 1989. p. 383-384.

KISCHINHEVSKY, Marcelo. Rádio em episódios, via internet: aproximações entre o podcasting e o conceito de jornalismo narrativo. Revista de la Asociación Española de Investigación de la Comunicación, Santiago de Compostela, v. 5, n. 10, p. 73-80, 2018.

KOBÍKOVÁ, Zuzana. Memex as the foundational stone of the hypertext theory. In: CER COMPARATIVE EUROPEAN RESEARCH, 2., 2014, London. Proceedings [...]. London: Sciemcee Publishing, 2014. p. 195199.

LANDOW, George. Hipertexto 3.0: La teoría crítica y los nuevos medios en una época de globalización. Barcelona: Paidós Ibérica, 2009.

LANDOW, George. La convergencia de la teoría crítica contemporánea y la tecnología. Barcelona: Paidós Ibérica, 1995.

LANDOW, George. Relationally encoded links and the rhetoric of hypertext. In: ACM CONFERENCE ON HYPERTEXT, 1987, Chapel Hill. Proceedings [...]. New York: ACM, 1987. p. 331-343.

LANDOW, George. Teoría del hipertexto. Barcelona: Paidós Ibérica, 1997.

LARRONDO URETA, Ainara. El reportaje hipermedia. Análisis del género en los especiales de Elmundo.es, Elpaís.com y Lavanguardia.es. Tese (Doutorado em Serviços Editoriais) - Universidad del País Vasco, Bilbao, 2009.

LARRONDO URETA. Ainara. La investigación sobre hipertexto: fundamentación teórica del ciberperiodismo y caminos para la docencia. Anàlisi: quaderns de comunicació i cultura, Barcelona, n. 36, p. 159-174, 2008.

LONGHI, Raquel. Escritura em hipertexto: uma abordagem do Storyspace. 2004. 122 f. Tese (Doutorado em Comunicação e Semiótica) - Programa de Pós-Graduação em Comunicação e Semiótica, Pontifícia Universidade Católica de São Paulo, São Paulo, 2004. Disponível em: https://tede2.pucsp.br/ bitstream/handle/4743/1/raquel_1protegido.pdf. Acesso em: 7 ago. 2020.

LONGHI, Raquel. Metáforas e labirintos: a narrativa em hipertexto na Internet. 1998. Dissertação (Mestrado em Comunicação e Informação) - Programa de Pós-Graduação em Comunicação e Informação, Universidade Federal do Rio Grande do Sul, Porto Alegre, 1998.

LONGHI, Raquel. Storyspace e ficção em hipertexto. In: CONGRESSO ANUAL EM CIÊNCIA DA COMUNICAÇÃO, 26., 2003, Belo Horizonte. Anais [...]. São Paulo: Intercom, 2003. Disponível em: 
https://www.academia.edu/38243658/Storyspace_e_fic\%C3\%A7\%C3\%A3o_em_hipertexto. Acesso em: 7 ago. 2020.

LONGHI, Raquel; WINQUES, Kérley. O lugar do longform no jornalismo online. Qualidade versus quantidade e algumas considerações sobre o consumo. In: ENCONTRO NACIONAL DA COMPÓS, 24., 2015, Brasília, DF. Anais [...]. Disponível em: http://www.compos.org.br/biblioteca/compos-2015-3c242f709168-4dfd-ba4c-0b444ac7347b_2852.pdf. Acesso em: 7 ago. 2020.

MIELNICZUK, Luciana. Jornalismo na web: uma contribuição para o estudo do formato da notícia na escrita hipertextual. 2003. 246 f. Tese (Doutorado em Comunicação e Cultura Contemporânea) Faculdade de Comunicação, Universidade Federal da Bahia. Disponível em: http://poscom.tempsite. ws/wp-content/uploads/2011/05/Luciana-Mielniczuk.pdf. Acesso em: 7 ago. 2020.

MIELNICZUK, Luciana. O link como recurso da narrativa jornalística hipertextual. In: CONGRESSO BRASILEIRO DE CIÊNCIAS DA COMUNICAÇÃO, 28., 2005, Rio de Janeiro. Anais [...]. São Paulo: Intercom, 2005. Disponível em: http://www.portcom.intercom.org.br/pdfs/16031829914038208160331140519321 1973269.pdf. Acesso em: 7 ago. 2020.

MIELNICZUK, Luciana; PALACIOS, Marcos. Considerações para um estudo sobre o formato da notícia na Web: o link como elemento paratextual. In: ENCONTRO NACIONAL DA COMPÓS, 11., 2002, Rio de Janeiro. Anais [...]. Disponível em: https://www.facom.ufba.br/jol/pdf/2001_mielniczuck_ linkparatextual.pdf. Acesso em: 8 ago. 2020.

NELSON, Ted. Complex information processing: a file structure for the complex, the changing and the indeterminate. In: ACM NATIONAL CONFERENCE, 20., Cleveland. Proceedings [...]. New York: ACM, 1965. p. 84-100.

NELSON, Ted. Literary machines. [S.l.]: Published by the author, 1987.

NELSON, Ted; SMITH, Robert Adamson; MALLICOAT, Marlene. Back to the future: Hypertext the way it used to be. In: ACM CONFERENCE ON HYPERTEXT AND HYPERMEDIA, 18., Manchester. Proceedings [...]. New York: ACM, 2007. p. 227-228.

ORIHUELA, José Luis. Nuevos paradigmas de la comunicación. Chasqui - Revista Latinoamericana de Comunicación, Quito, n. 77, p. 10-13, 2002. Disponível em: https://revistachasqui.org/index.php/ chasqui/article/view/1416. Acesso em: 8 ago. 2020.

PAJARES TOSCA, Susana. ¿Qué fue del hipertexto? [S.l.], 2003. Disponível em: http://jamillan.com/ celtos.htm. Acesso em: 8 ago. 2020.

PALACIOS, Marcos. Hipertexto, fechamento e o uso do conceito de não-linearidade discursiva. Lugar Comum, Rio de Janeiro, n. 8, p. 111-121, 1999.

PAVLIK, John. El periodismo y los nuevos medios de comunicación. Barcelona: Paidós Ibérica, 2005. 
PAVLIK, John. News framing and new media: digital tools to re-engage an alienated citizenry. In: REESE, Stephen D.; GANDY, Oscar H.; GRANT, August E. (ed.). Framing public life: perspectives on media and our understanding of the social world. New Jersey: Lawrence Erlbaum Associates, 2001. p. 311-321.

PÉREZ MARCO, Sonia. El concepto de hipertexto en el periodismo digital: análisis de la aplicación del hipertexto en la estructuración de las noticias digitales de tres periódicos españoles. 2003. 569 f. Tese (Doutorado em Jornalismo) - Universidad Complutense, Madrid, 2003.

PRYOR, Larry. The third wave of online journalism. Online journalism review, Los Angeles, v. 18, n. 4, 2002. Disponível em: http://www.ojr.org/ojr/future/1019174689.php. Acesso em: 8 ago. 2020.

RYFE, David; MENSING, Donica; KELLEY, Richard. What is the meaning of a news link? Digital Journalism, Abingdon, v. 4, n. 1, p. 41-54, 2016.

SALAVERRÍA, Ramón. Redacción periodística en internet. Pamplona: EUNSA, 2005.

SHARP, Naomi. The future of longform. The Columbia Journalism Review, New York, 9 dez. 2013. Disponível em: https://archives.cjr.org/behind_the_news/longform_conference.php. Acesso em: 8 ago. 2020.

SHIPMAN, Frank et al. Semantics happen: knowledge building in spatial hypertext. In: ACM CONFERENCE ON HYPERTEXT AND HYPERMEDIA, 13., College Park. Proceedings [...]. New York: ACM, 2002. p. 25-34.

STEENSEN, Steen. Online journalism and the promises of new technology: a critical review and look ahead. Journalism Studies, Abingdon, v. 12, n. 3, p. 311-327, 2011.

\section{NOTAS}

A discussão provocada neste artigo parte dos resultados da tese de doutorado (BACCIN, 2017b) que, além de discutir as especificidades do hipertexto jornalístico, propõe o reconhecimento do hipertexto como uma remediação do texto, aprofunda a discussão sobre a hipermídia, definindo-a como uma forma de mídia resultante da remediação de todas as formas de mídia, de linguagem e de modos expressivos midiáticos que a antecederam, e ainda identifica, a partir das características do hipertexto, os recursos que potencializam a contextualização das histórias nas reportagens hipermídia.

O Projeto Xanadu buscava criar uma biblioteca universal que funcionasse como um sistema de publicação de informações baseado em hipertextos. No entanto, o software Xanadu só ganhou vida quase meio século depois, em 2014. Nelson apresentou o conceito do software, chamado OpenXanadu (plataforma que mostra um documento e os textos utilizados para compô-lo), em um evento na Universidade Chapman, na Califórnia (EUA). 0 criador do hipertexto mantém a página em que explica o projeto inicial. http://xanadu. com/XanaduSpace/btf.htm. Acesso em: 8 ago. 2020.

3 Tim Berners-Lee e Robert Cailliau publicam a proposta para o hipertexto, disponível em: https://www. w3.org/Proposal. Acesso em: 8 ago. 2020.

Disponível em: https://dl.acm.org/conference/ht. Acesso em: 8 ago. 2020.

5 No original: “a material and visual field, whose properties are determined by a writing technology” (BOLTER, 2001, p. 12). 
No original: "the sum of the technical and social interactions that constitute a writing system" (BOLTER, 2001, p. 20).

8

No original: "El hipertexto se experimenta como un sistema que se puede descentrar y recentrar hasta el infinito, en parte porque transforma cualquier documento que tenga más de un enlace en un centro de pasajeros" (LANDOW, 2009, p. 89).

No original: “ para elaborar un mapa de las alusiones y referencias del texto, tanto internas como externas - su inter e intratextualidade” (LANDOW, 2009, p. 106).

gaining momentum, our social world is not yet enti and interconnected" (MAEYER, 2014, p. 538).

12

No original: "links can help reinforce a report's facticity by connecting readers directly with sources and showing readers how journalists know what they know" (CODDINGTON, 2014, p. 141).

13 Essa característica foi pensada a partir da análise de reportagens hipermídia, que serviram de corpus de pesquisa para a construção da tese de doutorado (BACCIN, 2017b).

14

No original: “El hipertexto se experimenta como un sistema que se puede descentrar y recentrar hasta el infinito, en parte porque transforma cualquier documento que tenga más de un enlace en un centro de pasajeros" (LANDOW, 2009, p. 89).

15 No original: “El rizoma es esencialmente un contraparadigma, no algo realizable en algún tiempo o cultura, pero que puede servir como ideal para el hipertexto, y el hipertexto, al menos el hipertexto nelsoniano ideal, se acerca tanto a él como cualquier creación humana” (LANDOW, 2009, p. 95). jerárquica de todo el conjunto" (LARRONDO URETA, 2009, p. 72).

$17 \quad$ No original: "ha de servirse de retóricas de orientación, navegación y punto de partida para orientar al lector" (LANDOW, 2009, p. 279).

Artigo recebido em 19 de junho de 2019.

\section{Artigo aceito em 02 de setembro de 2019.}

